\title{
DISCURSO DE FORMATURA (1)
}

\author{
DR. ANTONIO BRANCO LEFEVRE
}

Reunindo-nos nesta solenidade para festejar oficialmente a colação ide grau dos doutorandos em medicina da Universidade de São Paulo, sentimos todos, sem dúvida, sobresair da grande complexidade de sentimentos que agora nos assomam, um sentimento de imensa simpatia por todos os que estão ligados à primeira fase de nossas vidas: as gerações novas que se formam e os mestres que prosseguem na inţerminavel obra de formação médica è cultural. Surge-nos à memória a recordaçáo dos primeiros contatos com a me-
dicina, com os mestres e os colegas. Recordamos o principio de nossa vida escolar com suas preocupações e incertezas e passam assim novamente deante de nossas almas, velhas e queridas figuras que a preocupação das atividades sucessivas fazia julgar esquecidas. Surge-nos de início, viva como o era no momento em que nos deixou, aquela de Alfonso Bovero: figura vibrante, forte, austéra e amiga, particularmente cara para nós que fomos os últimos a entrar em contato com este espirito estremamente lúcido e creador. Alfonso Bovero foi um verdadeiro símbolo do espírito educativo da Faculdade de Medicina de São Paulo. Recebeu durante vinte e três anos todos os alunos desta escola, incutindo-lhes com seu exemplo de amor ao trabalho e à verdade científica, o impulso encorajador necessário para o encetamento da longa jornada do aprendizado médico.

\section{Sr. Prof. Benedito Montenegro.}

Sei que compreendestes o sentido que tiveram minhas palavras, evocando, embora assim rapidamente, antes de me dirigir a vós esta figura inesquecivel do mestre que partindo de nosso convívio tão cheio de força e de vitalidade, permanecerá sempre, congregando em torno de sua memória todos os que amam a Faculdade de Medicina de São Paulo.

Saudando-vos, Senhor Professor, nesta situação tão cara para todos nós, eu pósso vos assegurar que uma simpatia solidificada em momentos como este que vivemos agora, tem um carater definitivo e inabalavel. As palavras que de vós iremos ouvir certamente mar-

(1) Pronunciado na solenidade de colaçāo de grau dos médicos de 1941 da Faculdade de Medicina da Universidade de São Paulo. 
carão em nossas almas rumos esclarecidos e retos, ditadas, como o serão, pela vossa experiência e cultura hauridas no contato diário com os problemas médicos e humanos.

Ser-me-ia inutil procurar repetir o que tem sido' vossa atividade de mestre e de médico; dizem-no muito melhor vossos discípulos, formados à luz de vossos ensinamentos e de vosso exemplo, e que constituem hoje ramo do mais alto valor na medicina brasileira.

\section{MEUS COLEGAS :}

Seria limitar por demais o sentido desta solenidade, reduzí-la a um encontro de despedida em que se procurasse pela ressurreição de momentos já vividos, amenisar um instante de separação em que se rompem os laços tão vivamente soldados no longo decorrer destes oito anos de vida escolar. Este instante é muito mais do que isto: ele é, e principalmente, um instante de 'definição. E' a demarcação de um ponto de partida com que prestamos conta à sociedade e a nós mesmos. E' um instante de afirmação de fé, e como tal exige um sentimento exato de responsabilidade, necessitando ser vivido com esta imponência, neste ambiente distinto daquele a que estamos habituados, para que se saliente o seu carater de um momento fóra do tempo comum, como que uma parada no tempo, em que se prepara uma nova partida.

\section{POSIÇÃO DO MEDICO NO MUNDO MODERNO}

Os primeiros movimentos precursores da posição adotada pelo cientista moderno podem ser reconhecidos em KaNT que estabeleceu a situação da ciência como subordinada a algo que a ultrapassa que é a melhoria das condições de vida do homem, posição esta que se esclareceu com a noção formulada por NrETzSCHE orientando a pesquiza para os domínios da necessidade humana, limitando a ciência à importância do instrumento, e, definindo sua posição_de instrumento de especulação em uma primeira fase, mas com uma verdadeira finalidade prática, com o que perdeu ela o seu sentido de simples especulação intelectual permitindo que seu progresso revertesse num bem para a humanidade.

A história do desenvolvimento das ciências demonstrou que o seu progresso está. submetido a uma razão mais forte que o simples prazer da pesquiza pela pesquiza e que o verdadeiro impulso da ciência nasce das necessidades do homem. A coincidência dos estudos de NEwTon sobre o calculo infinitesimal terem surgido no momento em que se faziam necessários para a astronomia e para a navegação, é algo mais que uma simples coincidência pois representa a subordinação da ciência à sua verdadeira finalidade, posta ao serviço da humanidade. O progresso em biologia apresenta numerosas provas desta afirmação. Lembremo-nos por exemplo, do fato assinalado pelo 
Prof. Godoy Moreira em sua aula inaugural, e que é caracteristico do desenvolvimento paralelo de ciências aparentemente longinquas como a anatomia e a matematica: von Meyer e KuHLman chegando por estas vias tão diferentes a uma conclusão perfeitamente superponivel, desconhecendo um, inteiramente, os trabalhos do outro.

Onde situar a medicina no estado atual do progresso das ciências, renegada a ciência em sua finalidade única de "honra do espírito humano" (J

A compreensão dos fenômenos naturais - afirmou WALLACE em seu esclarecido estudo "The changing values of Science" - tornou respeitado e util o cientista da época moderna porem a substituição do "porque" pelo "como", ameaçou de colocar dentro de uma falsa concepção mecanista os processos mentais e fisiológicos pela aceitação do principio que condições semelhantes determinam fenomenos semelhantes, desde que sabemos que estas condições semelhantes não ocorrem.

No reajustamento de valores da ciência que se vem processando nos últimos anos - o cientista caminhando ao lado do filosofo procurando-se organiśár os conhecimentos dentro da constạtação de uma limitação imposta ao método por condições determinadas pela impenetrabilidade do íntimo dos processos orgânicos e psíquicos, a doutrina determinista, a que se deve a obtenção das leis que garantíram o progresso e a estabilidade das verdades biológicas, sofreu uma verdadeira crise, que implica senão em sua renuncia total, certamente num limite ao rigor e à universalidade que ela gozava anteriormente.

De qualquer forma a limitação da aplicabilidade de um principio anteriormente considerado ilimitado e definitivo, não indica a precaridade do método científico e sim mede a dificuldade da investigação e analise dos complexos fatores que regem a vida e a conduta dos seres, fatores que reagem a ser tratados como se fossem peças trabalhando sob regras puramente mecânicas.

A teoria dos quanta tornada necessária para a explicação de certos fenômenos do mundo atômico, os estudos de Broglie, BoHr e outros deram a HEISEMBERg as bases para formular a equação de incertezas, e, como resultado do deserrvolvimento dos estudos no terreno da física atômica, introduziu-se a dúvida no conceito da rigidez dos fenômenos físicos. A imprevisibilidade do movimento dos eletrons debilitou o método pelo qual o cientista chegou à sua constatação. Nesta lei da indeterminação o cientista de hoje encontra o limite permitido a suas investigações. Todavia é bom se assinalar que isto não significa a pregação de verdades definitivas, nem que se deva assumir a posição do cientista medieval que não admitia nenhum progresso na ciência depois de Aristoteles, mas sim que os dados. estabelecidos por ela devem ser a base de todos os raciocínios, permanecendo neutro o cientista ante a possibilidade de verdades que posteriormente se venham a estabelecer e que não podem ser previstas 
agora. A renegação do principio de causalidade, como fez EDDINGTON, não significa a renegação de tudo que este principio estabeleceu nem a introdução de um elemento volitivo na natureza inanimada, é apenas a aceitação dos limites impostos ao trabalho cintífico. O plano de trabalho de Herbert Dingle é característico deste espírito. Deve-se construir uma base, afirma Dingle, sobre a qual o cientista deve trabalhar, na área mais limitada que lhe seja possivel avaliar pela exploração com os meios limitados que dispomoss, e construir sobre este núcleo central até que uma teoria mais geral possa se estabelecer.

"Le hasard règne dans le microscosme" e esta situação aparentemente paradoxal a que conduziu o desenvolvimento do pensamento científico em lugar de produzir um cáos como o fez a descoberta de Galileu, deu a marca de uma das características mais notáveis do pensamento contemporâneo - como lembra William White - que é a possibilidade de se quebrar a tradição com relativa facilidade quando esta perde as bases sobre as quais repousava.

A época moderna pode mesmo ser chamada a época das limitações. O cientista cujo espírito de investigação havia ultrapassado os valores reais da ciência é obrigado a constatar a impropriedade de seu avanço.

Já no terreno dos processos mentais havia surgido uma limitação, embora d'e outra ordem, à penetração do íntimo do espírito humano pela investigação e analise do inconciente. A fenomenologia, a moderna corrente do pensamento filosófico alemão, surgiu como uma reação à psicanalise de FREUD, assinalando que esta apenas liberta o indivíduo sem lhe indicar um caminho a seguir que evite seu retorno à situação anterior. A fenomenologia reagiu contra a ausência de sentido construtivo da psicanalise que apenas precisa o mecanismo de interiorisação mas não edifica nada sobre o terreno livre dos obstáculos, não cogita do fim d’o homem.

O rumo do pensamento científico moderno é como o disse PusCARIU em sua conferência "Pensée et philosophie scientifique" - a assimilação das noções retiradas da lei de indeterminação, baseada em relações de probabilidade dos fenomenos fundadas no método estatístico cujo cantpo estendeu-se enormemente oferecendo possibilidades insuspeitadas quando posto ao serviço do progresso pela aquisição de leis gerais.

A biologia está, pode-se dizer, à espera de uma síntese que abranja dentro deste espírito a imensidade de aquisições com que a enriqueceram as grandes descobertas dos séculos XIX e XX, époça em que se alicerçou um progresso que o homem de hoje exige que se codifique.

A razão de se trazer a uma solenidade como esta noções que colocam uma barreira num campo que há poucos anos estendia-se sem limites, encontra seu sentido na constatação ıde um fato que é um dos 
problemas mais sérios da medicina contemporânea e que é a ausência do homem no médico.

Esta afirmação aparentemente agressiva e despropositada é explicada entretanto pela importância que o médico dá à medicina, procurando torná-la uma ciência partindo da equiparação do organismo humano a algo de profundamente hostil à sua natureza essencialmente movel e instavel. Fechando os olhos à existência de um campo em que penetra o homem e pára o cientista, procurou o médico acomodar o organismo humano à estrutura de um mosaico com elementos rigidos tirados da anatomia patológica, creando leis mais ou menos gerais confirmadas pela experimentação, e reduzindo o psiquismo à ilusão simplificadora dos reflexos condicionados.

Pode isto parecer uma forma nova de se exprimir uma antiga situação: o médico procurando padronisar os tipos humanos numa ansia de simplificação, e o homem se oponto a esta impersonalisação no uniforme. De qualquer forma, dentro da situação atual do mundo não há lugar para esta oposição, visto como o homem de hoje, angustiado e desnorteado pela convulsão de todos os valores, merece de seu médico um tratamento liberto de fórmulas frias e estandartisadas que nãơ procuram conhecer os característicos individuais que são a base sobre a qual se deve estabelecer toda a tentativa de contatos humanos.

As relações do médico e do doente evoluiram sempre e cada vez mais no sentido do prósaismo até colocar, como na época atual, um homem deante de outro homem. O médico foi pouco a pouco perdendo as virtudes mágicas e milagrosas que o apartavam do comum dos homens. Sigerist em sua "Introduction à la Medicine" refere-se aos "chamanes", os médicos de certas tribuns siberianas que eram considerados verdadeiros intermediários entre o mundo dos homens e dos espíritos, sendo honrados e principalmente temidos pelos clientes. Em certas regiões formava-se mesmo um "chamanismo" hereditário, sendo as virtudes superhumanas transmitidas de pais a filhos, e, em outras, mais exigentes, tornavam-se "chamanes" aqueles que para isto haviam sido indicados por qualquer sinal extraordinário - os que nasciam com uma dentadura completa ou que demonstravam ter sido alvo de algum milagre tal como cair de uma arvore alta sem quebrar nem ao menos uma perna.

O médico da farça molieriana é um tipo intermediário que permite prever o médico de Marcel Proust, simbolos os dois de duas fases do mesmo processo de prosaismo nas relações do cliente e do médico. O médico de MolıÈre tenta ainda disfarçar a evidência da incompreensão, revestindo-se da simulação do fraseado pomposo, enquanto que CoTARD, grande professor, já é um homem como qualquer outro e como tal precisa compreender e explicar, podendo ser julgado, como o foi "Il a prévu la difficulté de gérer les sauces, l'emba raś gastrique, mais n'a pas prévu la lecture de ShaKespeare”. 
Despido de seus atributos sobrenaturais e reduzido à simplicidade dos contactos humanos, o médico de hoje tem que viver no seio dos homens compartilhando de suas angústias, e, em vez de se por comodamente à margem dos conflitos sociais e políticos precisa viver neles mergulhado pois só assim poderá compreender — não excepcionalmente mas como atitude diária - a solidarisação em que se fundem a alma e o corpo doentes.

Este esboço mede a imensa dificuldade com que luta o médico de hoje, necessariamente coparticipante dos problemas dos homens, com a obrigação de se manter ileso, em função de sùa própria atividade médica.

A oração de Hipocrates, que hoje repetimos, é o código de ética da medicina ocidental, as suas palavras eternas encerrando todo o sentido da medicina que é o de socorrer. Ao médico cabe sentir o ideal de sua época, diz Sigerist. A base da medicina é o amor, disse Paracelso. Estas formulas estabelecem o rumo da atividade médica que deve ter como finalidade socorrer, por amor aos homens, dentro do espírito de sua época.

Hipocrates e Freud foram grandes médicos. Ocuparão para sempre um lugar de honra na história da medicina, ao lado daqueles que souberam se aproximar do ideal médico de seu tempo, desde que aceitamos que o conceito do ideal médico não significa somente notar e seguir as predileções evidenciadas pela medicina de uma época orientada para um ramo de estudos, mas é muito mais do que isto pois cada época tem o direito de exigir outra coisa de seu médica; tem o direito de exigir a simpatia originada nas ligações comuns a todos os homens realisadas através das imposições da estrutura social desta época.

KARDINER estudando as psicoses determinadas pela guerra em seu recente livro "The traumatic neuroses of war" concluiu que, certamente, a guerra, particularmente a guerra moderna crea situações extremamente propícias aos traumas psiquicos.

Aliás, já as observações de Aunokatow tinham demonstrado o grande aumento no número de casos de epilepsia como consequencia da guerra Russo-Japonesa. Kardiner estudou o papel da guerra como causa determinante de traumas psíquicos específicos e modificadora da evolução dos traumas comuns; estudou os fatores que intervem no desencadeamento destas neuroses e o seu colorido particular e combateu as teorias organicistas que procuram explicar estes fenômenos pela formula simplificadora da "insuficiência orgânica".

A atividade do médico que sente o ideal ide nossa época, não pode entretanto se limitar a estas grandes manifestações patológicas mas também deve procurar adaptar o conceito de normalidade às novas condições da sociedade transformada.

O homem de hoje, de quem diz Bernanos, "Ce que je vois d'abord dans l'homme c'est son malheur", precisa e deve ser compreendido dentro de conceitos libertados de formulas tradicionais e 
prefixadas, deve ser compreendido dentro de uma noção de realidade cultivada no íntimo da experiência humana. E esta atitude evidentemente transborda o campo especialisado da psiquiatria e deve ser o colorido obrigatório de toda a atividade médica.

Não posso deixar de transcrever a página de NiETzsche que sitúa em toda sua extensão o problema das relações humanas na medicina “... hoje a formação intelectual mais avançada de um médico não 'é atingida quando ele conhece e sabe se servir dos métodos melhores e mais recentes e quando sabe estabelecer as delicadas relações de causa e efeito que dão a firmeza ao diagnóstico. O médico deve ainda ser dotado de uma eloquência que se adapte a cada indivíduo e penetre até o mais profundo de cada um deles; uma energia viril cuja vista apenas faça fugir o desencorajamento; a habilidade de um diplomata no contacto com aqueles que necessitam alegria para sua cura; uma frieza de policia e advogado para compreender os segredos de uma alma sem os trahir. Assim armado, conclue NiETzSCHE, ele será um bemfeitor da humanidade provocandb a formação de uma aristocracia intelectual e corporal".

O médico de hoje não pode desconhecer as exigencias que the impõe a sociedade moderna ainda em plena transição, em pleno cáos, em busca de afirmações que substituam os valores que as grandes transformações deste século abalaram.

Somente participando desta busca saberá o médico de hoje mostrar-se digno da eterna mensagem de paz de que é portador.

\section{O departamento de}

\section{ADMINISTRAGAO PREDIAL}

DA

\section{Caixa Geral de Emprestimos}

REGULARIZARÁ E AUGMENTARÁ O RENDIMENTO DOS PREDIOS DE V.S.

IDONEIDADE ABSOLUTA

PRESTAÇÃO RIGOROSA DE CONTAS

\section{CAIXA GERAL DE EMPRESTIMOS}

Caisse Générale de Prêts Fonciers et Industriels

Rua Tabatinguera, 164 - Fone 2-4722 - SÃO PAULO 


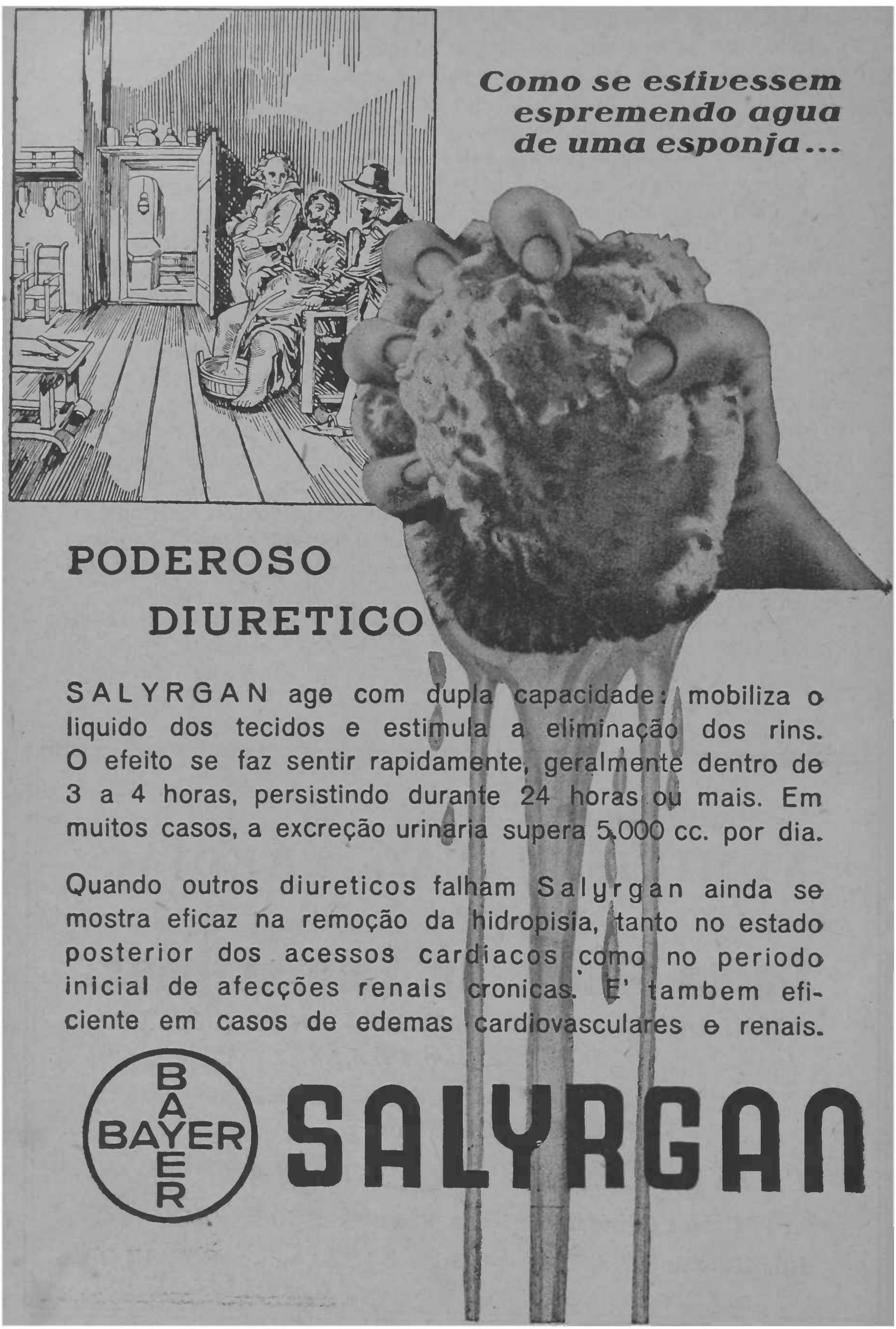

